\title{
INMIGRACIÓN Y RACISMO: EXPERIENCIAS DE LA NIÑEZ PERUANA EN SANTIAGO DE CHILE ${ }^{1}$
}

\section{Inmmigration and racism: Experiences of Peruvian childhood in Santiago, Chile}

Iskra Pavez Soto ${ }^{2}$

Universidad Alberto Hurtado, Santiago, Chile.

Recibido: 29 de abril de 2011. Aprobado: 17 de octubre de 2011.

\author{
"Escolares chilenos aceptan más a los peruanos si adoptan nuestra \\ cultura por sobre la propia" (Elqueda 2008)
}

\begin{abstract}
RESUMEN
El objetivo de este artículo es analizar las experiencias de discriminación y racismo que han vivido las niñas y los niños peruanos inmigrantes en Santiago de Chile, a partir de la perspectiva de género y la comprensión teórica de la sociología de la infancia, que entiende a este como grupo social con capacidad de agencia. Se constata que el contexto social y económico determina situaciones de precariedad y exclusión para las familias peruanas; un escenario que agudiza la discriminación y el racismo basado en el "origen peruano" como un signo de la vulnerabilidad. Con todo, la migración infantil constituye una oportunidad de espacios de participación, reflexión y actoría infantil a nivel familiar, social y escolar.
\end{abstract}

PALABRAS CLAVE: Niñez migrante, racismo, discriminación.

1 El presente artículo forma parte de los resultados de mi tesis doctoral de Sociología, cuyo objetivo general es analizar sociológicamente la migración infantil de las niñas y los niños peruanos, junto con sus familias, en Barcelona y Santiago de Chile.

2 Doctora en Sociología y magíster en Sociología por la Universidad Autónoma de Barcelona y Trabajodora Social por la Universidad Tecnológica Metropolitana. Actualmente es directora de la Escuela de Trabajo Social de la Universidad Alberto Hurtado. Correo electrónico: ipavez@uahurtado.cl 


\begin{abstract}
This article analyzes the discrimination and racism experienced by children of Peruvian immigrants in Santiago, Chile, using gender perspective and a theoretical understanding of the sociology of childhood, which considers children a social group capable of agency. There is evidence that socio-economic context creates situations of exclusion for Peruvian families, a scenario that aggravates discrimination based on "Peruvian origin" as a sign of vulnerability. Finally, child migration represents a chance for participation, reflection and childhood agency at the family, school, and community levels.
\end{abstract}

KEYWORDS: Migrant childhood, racism, discrimination.

\title{
I. INTRODUCCIÓN
}

El objetivo de este artículo es analizar las experiencias de discriminación y racismo que han vivido las niñas y los niños peruanos en Santiago de Chile, a partir de la perspectiva de género y la comprensión teórica de la sociología de la infancia, que entiende a este como grupo social con capacidad de agencia.

Las migraciones internacionales comienzan a ser paulatinamente un fenómeno de interés público para la sociedad global y en particular para la chilena. La población peruana residente en el país ha aumentado en forma sostenida durante los últimos años y en la actualidad representa el mayor grupo extranjero. Además, la llegada de sus hijas e hijos en años recientes ha demostrado su intensión de instalarse en el lugar de destino. Por lo tanto, el estudio de los procesos migratorios y las experiencias de racismo y discriminación que viven las personas extranjeras resultan de gran interés social, económico, político y eminentemente académico. En particular, la situación que vive la niñez inmigrante merece una especial atención no solo de parte de las instituciones públicas, sino también de parte de los estudios sociológicos. En este sentido, el presente artículo también pretende contribuir al debate público sobre la situación de vida de las niñas, los niños y las familias peruanas migrantes, con especial énfasis en aquellas prácticas que generan discriminación y exclusión, y por lo tanto, obstaculizan los procesos de integración y cohesión social en Chile.

Los datos que se presentan a continuación provienen de bibliografía especializada sobre las migraciones contemporáneas. También se presenta información extraída del 
trabajo de campo donde se realizó observación participante en organizaciones sociales ${ }^{3}$ y en dos escuelas públicas con alta presencia de alumnado extranjero en Santiago; ${ }^{4}$ a partir de esta inserción se realizaron 15 entrevistas con niñas, niños y familias peruanas. ${ }^{5} \mathrm{La}$ categorización se realizó con el programa informático Atlas Ti a través de la técnica del análisis crítico del discurso (Van Dijk 2003).

El artículo es estructura en tres grandes apartados. En primer lugar se revisan algunos conceptos teóricos sobre la niñez que participa en la migración, los cuales sustentan nuestro estudio y el posterior análisis de la información. En segundo lugar se presentan sucintamente algunos datos del contexto específico de la migración peruana en Chile, en especial sobre los procesos de feminización e incorporación escolar de la niñez. Por último se analizan los discursos infantiles referidos a las experiencias de discriminación y racismo, y se cierra el artículo con algunas conclusiones generales.

\section{NIÑEZ Y MIGRACIÓN: UNA REVISIÓN CONCEPTUAL CRÍTICA}

Tanto la niñez como la migración son fenómenos sociales contemporáneos que desde una visión sociológica presentan una gran complejidad, debido a las múltiples dimensiones que cada uno de ellos engloba y, sobre todo, cuando las niñas y los niños participan, de diversas maneras, en los procesos migratorios. En el presente apartado intentamos reflexionar críticamente sobre los conceptos teóricos en el estudio de la infancia, con especial énfasis en la situación específica de aquella niñez construida y vista socialmente como "inmigrante".

\section{Sociología de la infancia: niñas y niños como actores sociales}

La sociología de la infancia con mayor tradición anglosajona ofrece una perspectiva global y crítica sobre el fenómeno de la infancia en nuestras sociedades, aunque en nuestro ámbito hispanoamericano esta mirada continúa marginal dentro de los estudios sociales. La infancia es aún objeto de difícil investigación parcelada entre el estudio de la familia o la educación. Un paradigma sociológico específico que se dedique a estudiar

3 El trabajo de campo se desarrolló en el Colectivo Sin Fronteras, a cuyos miembros agradezco infinitamente su colaboración en este estudio.

4 Las escuelas donde se llevó a cabo la observación participante fueron la Escuela República Colombia y Escuela República Panamá, ambas del municipio de Santiago-centro.

5 Todos los nombres son ficticios para proteger la confidencialidad de los datos recogidos y el derecho a la intimidad de las niñas y los niños. 
este fenómeno social permite repensar el concepto contemporáneo de infancia, complementar e incluso enriquecer la variedad de enfoques científicos para su estudio. La sociología de la infancia se comprende como un campo de estudios emergente y con un fuerte carácter multidisciplinar (Qvortrup 1992, 1994; Rodríguez 2000:100; Gaitán 2006b:49).

Desde este punto de vista sociológico se estudia a la infancia como una construcción social variable en términos históricos, económicos y políticos, enriqueciendo el concepto psicológico o pedagógico de la niñez entendida solo como una fase en el desarrollo individual y de socialización para la vida adulta, ya que visibiliza la dimensión política del fenómeno de la niñez. En síntesis, la infancia en términos sociológicos es vista como un grupo social en relaciones de poder, conflicto y negociación con los otros grupos sociales, complejizando el nivel individual de la vida infantil y otorgándole dimensiones sociales y políticas (Qvortrup 1992; Wintersberger 1994).

Gaitán señala que se entiende la niñez como un "espacio socialmente construido para que lo habiten las niñas, los niños y adolescentes, es decir, donde transcurre su vida" (2006a:33). Frønes añade que "la infancia es el periodo de la vida durante el cual un ser humano es tratado como un niño con las características culturales, sociales y económicas que acompañan este periodo" (1994:148). A esta definición habría que añadir que dicho espacio social y el trato es similar en términos generacionales, pero bastante diferenciado en términos de género (Pavez 2011a).

Desde el punto de vista estructural, se entiende la infancia como una categoría sociológica que existe permanentemente en la sociedad, aunque sus miembros se renueven constantemente (Qvortrup 1992, 1994; Wintersberger 1994). En nuestro tema de estudio, podemos comprobar que la categoría sociológica de la niñez extranjera existe permanentemente; de hecho, es ocupada por determinadas niñas y niños, pero va transformándose en términos históricos según el predominio de ciertas nacionalidades, por ejemplo, en los flujos migratorios contemporáneos hacia Chile.

Si bien la infancia como categoría existe de manera permanente en la estructura de todas las sociedades, en cada contexto en que se desarrolla el fenómeno de la infancia se identifican especificidades. La infancia no es homogénea. Al interior del grupo infantil se dan diferencias y desigualdades de género, de clase social o de origen étnico-nacional. En cada territorio y momento histórico han sido distintas las expresiones del fenómeno de la infancia y, por lo tanto, el concepto mismo de infancia. En este sentido, este enfoque sociológico identifica distintas formas de ser niña o niño, es decir, se reconocen diversas "infancias" que comprueban su construcción social (Jenks 1996). 
Como todo fenómeno social, la vida concreta de las niñas y los niños se ve afectada por las estructuras económicas y políticas de cada contexto. La acción social del agente infantil, entendida como la capacidad de agencia de los actores sociales, se da en un marco estructural donde la posición infantil se halla subordinada a la autoridad del grupo adulto. A pesar de que las niñas y los niños tienen un margen de acción minoritario para desenvolverse, de todas maneras desarrollan su acción social, pero esta es poco reconocida por la sociedad adultocéntrica (James y Prout 1997:x; Mayall 2002:21). Desde la mirada sociológica, la infancia se considera como una generación con un estatus y una posición de poder determinada. Reconociendo que las niñas y los niños desarrollan relaciones generacionales de poder y negociación, en convergencia con el orden de género patriarcal y están constituidas también por este (Alanen 1994; Mayall 2000, 2002).

En el caso de la niñez que participa en procesos migratorios familiares, según Gaitán (2008) es preciso que se den dos condiciones para que los niños y las niñas sean considerados como actores sociales. En primer lugar, es preciso que ellas y ellos desarrollen acciones e incidencia en su propia vida y en el entorno que habitan. En segundo lugar, es necesario que dicha acción social sea reconocida por los otros actores sociales, tanto por su familia como por las instituciones de la sociedad de origen y de destino. Sin embargo, esta última condición es difícil que se cumpla, porque en general a los niños y las niñas se les trata como "objetos" pasivos y receptores de las decisiones y protección adultas (adultismo), y no como sujetos que sí actúan dentro del marco minoritario de poder que tiene para hacerlo.

\section{La "condición inmigrante" de la niñez}

La participación de las niñas y los niños en la decisión de su propia migración también ha generado un interesante debate conceptual. En este sentido, Gaitán (2008) señala que generalmente el fenómeno de la niñez afectada de alguna manera por la migración, presenta dos limitaciones teóricas importantes. En primer lugar se trata de fenómenos estudiados generalmente desde los países de destino, imprimiendo un inevitable sesgo etnocéntrico en el análisis; ya que se presupone que es allí (en el lugar de destino) donde la familia se reunirá nuevamente en virtud de una visión lineal del proceso migratorio que comienza con la migración adulta y "termina" con la llegada de las hijas e hijos. Sin pretenderlo, se recrea una determinada visión normativa del grupo familiar, esencialmente nuclear, sin considerar los arreglos y las estructuras familiares diversas de cada territorio. Además, Pedone (2010) ha demostrado que los procesos migratorios 
siguen tendencias transnacionales complejas que no son lineales, sobre todo en tiempos de crisis, generando movilidades familiares de retorno y emigración constantes.

En segundo lugar, generalmente se estudia el proceso migratorio familiar desde la perspectiva adulta, lo que denota un sesgo adultocéntrico. Con el objetivo de avanzar hacia una investigación centrada en la situación infantil (child centered), Gaitán (2008) propone analizar la movilidad familiar con la atención puesta en la experiencia migratoria infantil. Desde la sociología de la infancia resulta revelador investigar la participación de las niñas y los niños en la decisión de la migración adulta y especialmente en su propia migración, ya que estos procesos de toma de decisión significan una expresión de las relaciones generacionales de poder en que participan en sus familias y en los procesos migratorios globales, en tanto actores sociales. Si bien algunas niñas y niños no quieren ni deciden migrar, de todos modos se ven afectados ineludiblemente por la migración familiar, la cual cambiará en forma radical sus vidas (Pavez 2011a y 2011b).

Cuando las niñas y los niños participan en procesos de movilidad familiar, la sociedad de destino utiliza variados y contradictorios criterios para construir y posicionarlos en la categoría sociológica de "inmigrantes". Al igual que ocurre con las personas adultas inmigrantes, las niñas y los niños se consideran culturalmente diferentes (alteridad) respecto de la sociedad anfitriona (homogénea supuestamente); y por haber participado en una socialización y educación en valores de las familias de origen inmigrante, se piensa que comparten los rasgos que les hacen diferentes (Santamaría 2002). Por otro lado, aquellas hijas e hijos que se identifican como "inmigrantes", no son todos los descendientes de personas extranjeras, sino muy especialmente quienes provienen de familias con un determinado nivel socioeconómico y de países empobrecidos. ${ }^{6}$

Según García (2008:30 y ss.), criterios tales como el lugar de nacimiento, la nacionalidad o el desplazamiento geográfico se utilizan en los lugares de destino para etiquetar a determinadas personas como "inmigrantes". Para el caso que nos ocupa, a pesar de que las hijas e hijos "de inmigrantes" nazcan en los países de destino, tengan dicha nacionalidad y no hayan vivido procesos de movilidad, de todos modos son interpelados socialmente como "inmigrantes". Por el hecho de que las familias inmigrantes provengan de otra sociedad y cultura, dichas diferencias (sociales) se interpretan como

6 La palabra migración significa literalmente un movimiento espacial de un lugar a otro. Pero no todos los desplazamientos son considerados socialmente como migraciones (por ejemplo, aquellos de las personas provenientes de países ricos). 
inherentes a su condición humana de existencia (personales), que no dependen de su lugar de nacimiento, movilidad o nacionalidad. ${ }^{7}$ El estigma que recae sobre las niñas y los niños de ciertas familias extranjeras los equipara a la situación migratoria de sus madres y padres. En palabras de García (2008:39), las niñas y los niños heredan la "condición inmigrante" de sus ascendientes mediante un complejo mecanismo sociobiológico ("si naces de personas inmigrantes y te educas como inmigrante, eres inmigrante"). Para García (2008:46), las diferencias culturales se utilizan a menudo como una forma de canalizar los prejuicios hacia sociedades que se consideran inferiores. Justamente es este el contexto de las migraciones peruanas contemporáneas hacia Chile, como se verá en el siguiente apartado.

En este escenario, una de las cosas más difíciles que deben enfrentar las niñas y los niños durante el proceso migratorio son las situaciones de discriminación o racismo en los lugares de llegada. Tal y como señalan Suárez-Orozco y Suárez-Orozco $(2003,2008)$, la sociedad de destino les refleja -como un espejo social-determinadas imágenes sobre sí mismos, especialmente cuando se trata de ciertos colectivos sobre los cuales recaen estereotipos negativos. Estas imágenes son difundidas constantemente en los medios de comunicación, en el aula o en la calle, lo que termina por afectar la autoestima y esperanzas de integración. Si la imagen social reflejada es positiva, el individuo se siente digno y competente, con altas posibilidades de sentirse integrado. Mientras que la actitud de respuesta de las niñas y los niños inmigrantes ante las imágenes negativas pueden ser variadas y van desde la asunción de dicha identidad negativa, pasando por ignorarla, o bien desarrollando una resistencia activa, todas estas actitudes influyen en el tipo de adaptación infantil (Suárez-Orozco y Suárez-Orozco 2003:167; Alegre 2007:11). Lo anterior refleja que las niñas y los niños inmigrantes comparten una doble posición social: por un lado, la edad que constituye una jerarquía generacional y la categoría inmigrante que se fundamenta en un orden étnico-nacional (Alegre 2007; García 2008). A esto habría que añadir la condición de género como otro eje generador de desigualdades sociales (Pavez 2011a).

Con todos estos elementos teóricos y conceptuales intentamos aproximarnos hacia el concepto de "migración infantil" que permita conocer la experiencia de movilidad en que participan las niñas y los niños peruanos hacia Chile.

$7 \quad$ En este sentido, en España existe un debate académico sobre la pertinencia estratégica de adoptar el concepto anglosajón de "segunda generación de inmigrantes" a determinados grupos de hijas e hijos de personas extranjeras, en particular para quienes no han vivido procesos de movilidad territorial. Además, Suárez (2006) critica el que sea una etiqueta que recae sobre países empobrecidos y familias en situación de exclusión social. 


\section{Contextos de la migración peruana en Chile}

En este apartado se presenta brevemente el contexto de los procesos migratorios peruanos contemporáneos hacia Chile. Para ello consideramos tanto la información estadística disponible a partir de las fuentes oficiales de registro, como los factores que inciden en la feminización y los recientes procesos de migración infantil donde comienza a percibirse la mayor participación de las niñas y los niños. Por último se discuten las experiencias de escolarización de la niñez peruana en Chile, donde se constata que aún quedan bastantes desafíos para lograr una verdadera integración social.

\section{Caracterización sociodemográfica de la niñez peruana en Chile}

Según el último Censo de 2002, se contabilizan 184.464 personas extranjeras viviendo en Chile, lo que representa el 1,22 por ciento del total de la población. ${ }^{8}$ De esta cifra, 96.340 son mujeres y 88.124 son hombres. Según los datos del Censo 2002, después del grupo argentino las personas peruanas representan el segundo grupo mayoritario de inmigrantes en Chile. Pero, tras el proceso de regularización realizado entre 2007 y 2008, los datos oficiales del Ministerio del Interior muestran que hay 290.901 extranjeros residentes en Chile, provenientes en su mayoría de Perú, Argentina, Bolivia y Ecuador, de esta cifra el 52 por ciento son mujeres, es decir, continúa la tendencia hacia la feminización de la migración contemporánea. En particular, el índice de feminidad del grupo peruano es del 66 por ciento, mayor al promedio de los otros grupos extranjeros en Chile (Stefoni et al. 2008:12).

La comunidad peruana tiene un destacado peso en relación a los otros grupos nacionales, incluso supera al colectivo argentino que en los registros censales aparece como el grupo extranjero más grande. ${ }^{9}$ Claramente se observa que la comunidad argentina lleva más tiempo de asentamiento en Chile, porque durante el período 1995 a 2005 obtiene 76.323 visas, mientras el colectivo peruano en esa década solo obtiene 33.003. No obstante, a medida que pasan los años crece sostenidamente el número de visas concedidas a las personas peruanas, llegando a una cifra récord de 28.203, solo durante el año 2009 (Departamento de Extranjería y Migración, Ministerio del Interior de Chile 2010a y 2010b).

8 En términos absolutos es la mayor cifra registrada en la historia del país, pero en términos relativos es inferior al 4,1 por ciento registrado en 1907, con 132.000 personas. Y también es inferior a la media mundial del 3 por ciento (Martínez 2003a).

$9 \quad$ Si bien la presencia peruana es mayoritaria (83.352 personas), estos datos por sí solos no reflejan el número total de residentes en Chile, porque únicamente registran el número de visados otorgados; por lo tanto, a estas cifras habría que añadir los casos de quienes se encuentran en situación administrativa irregular, pero se desconocen estas cifras. 
Según grupos de edad, a partir del Censo 2002 se aprecia que la mayoría de las personas extranjeras en Chile tiene entre 15 y 29 años, seguidas de las personas adultas en edad laboral desde los 30 a 44 años; luego le siguen las niñas y los niños con menos de 14 años, y el último grupo lo conforman las personas mayores de 45 años. El 57 por ciento de la población extranjera se halla entre los 15 y los 44 años de edad, es decir, en plena etapa laboral, lo que responde a las propias características de la migración contemporánea (Martínez 2003a).

A inicios del año 2007, de acuerdo al Ministerio del Interior, del total de personas extranjeras residentes en Chile, solo el 18 por ciento tiene menos de 15 años. En esta ocasión, las niñas y los niños peruanos son el grupo mayoritario dentro de la niñez inmigrante en general: en términos absolutos son 58.433 efectivos, pero en términos relativos continúan representando solo el 10 por ciento dentro de la propia comunidad peruana. La presencia infantil en otros grupos nacionales de la región sudamericana continúa la tendencia de los datos del Censo 2002: Argentina registra el 31 por ciento de menores de 15 años dentro de su grupo nacional (53.801); Ecuador, 18 por ciento (11.765); y Bolivia, 10 por ciento (13.538) (Flores 2007:95).

\section{Procesos transnacionales de movilidad: de la feminización a la migración infantil}

Al igual que sucede en los países ricos, durante los últimos años la economía chilena ha crecido y, con ello, la demanda de mano de obra extranjera. Ya vimos que el grupo peruano es el mayoritario en el país y está compuesto principalmente por mujeres, quienes por lo general ingresan a trabajar en el servicio doméstico. Algunos de los factores que inciden en estos procesos, desde el punto de vista del contexto de recepción, se relacionan con la necesidad de las familias chilenas de clase media y alta por contratar a personas que realicen el trabajo reproductivo (doméstico y cuidado) en sus propios hogares. Dado que no existen estrategias de corresponsabilidad doméstica en términos de género, ni políticas públicas en esta materia, cuando las mujeres chilenas no pueden o no quieren realizar este trabajo -hecho de modo gratuito históricamente- se contrata a las "nanas", mujeres más pobres y en el último tiempo inmigrantes, para que las "reemplacen" en esta labor (Stefoni 2002:135, 2009:195; Programa de las Naciones Unidas para el Desarrollo 2010). ${ }^{10}$

De acuerdo a Martínez (2003a:28, 45, 48; 2003b), el 70 por ciento de las mujeres peruanas inmigrantes en el país trabaja en el servicio doméstico, y de todas las extran-

10 Esta situación queda muy bien representada en la película chilena llamada justamente La nana (2009), dirigida por Sebastián Silva, la cual ha obtenido numerosos premios en festivales internacionales, entre los cuales cabe mencionar que fue nominada a los Globos de Oro. 
jeras que trabajan en este rubro, las peruanas representan el 80 por ciento. De este porcentaje, cerca del 30 por ciento de mujeres peruanas trabaja en la modalidad de "puertas adentro". Mientras que las chilenas como "internas" representan solo el 18 por ciento dentro de esta actividad. Es evidente, pues, la alta concentración de mujeres peruanas en el servicio doméstico chileno. ${ }^{11}$

En términos de la distribución de género, además del servicio doméstico, las mujeres peruanas se insertan en el comercio e industria; mientras que los hombres peruanos trabajan en servicios, comercio, construcción e industria. Cerca del 20 por ciento de las mujeres peruanas que trabajan en el servicio doméstico son profesionales universitarias y/o técnicas, una cifra superior incluso al 16 por ciento de los hombres peruanos inmigrantes que tiene un nivel técnico (Martínez 2003a:28, 45, 48; 2003b). En general, la población peruana inmigrante presenta tasas de actividad laboral más altas que los otros grupos nacionales. Por ejemplo, las peruanas doblan el nivel de incorporación laboral de las chilenas, lo que constituye una importante contribución productiva para el país (Stefoni 2002:131).

Cuando recién llegan al país, la mayoría de las mujeres peruanas pioneras de la migración, trabajan en la modalidad de "puertas adentro"; es decir, viven en sus lugares de trabajo, ubicados mayoritariamente en el barrio alto de la capital. De este modo, ahorran en los gastos de comida y alojamiento para enviar mayores remesas a sus familias en Perú. A pesar de que los sueldos son bajos y las condiciones laborales muy precarias, con tendencias hacia la explotación, algunas mujeres peruanas sienten que es un empleo estable por el cual reciben mayor remuneración que sus empleos en Perú -incluso cuando trabajaban en puestos técnicos y profesionales- (Stefoni 2002:128; 2009). Una vez que las mujeres inmigrantes logran instalarse definitivamente en destino (en términos de estabilidad laboral e integración social) deciden consolidar el proyecto migratorio familiar gestionando la migración de sus parejas, hijas e hijos. Para ello alquilan una vivienda en comunas que ofrezcan una oferta habitacional accesible y alquileres más baratos, habitualmente en los alrededores de Santiago. La migración infantil se interpreta como la voluntad de establecerse definitivamente en Chile, al menos por un largo período (Martínez 2003a:39; Stefoni 2004:324; Stefoni et al. 2008:39). Desde el año 2004 comienza a registrarse la llegada de las niñas y los niños peruanos tras un promedio de cinco años separados de sus madres y padres, al cuidado de otras personas en sus países de origen

11 Las mujeres inmigrantes que se emplean como "nanas" ocupan puestos de trabajo que han sido abandonados por las mujeres chilenas. Según datos de la Encuesta de caracterización socioeconómica, en la década de 1990 la participación en el servicio doméstico baja de 7,6 por ciento a 4,7 por ciento, es decir, las mujeres chilenas se retiran de esta actividad. Por lo tanto, la inserción de las mujeres peruanas en el servicio doméstico se puede denominar de carácter complementario, ya que ellas ingresan a un nicho laboral abandonado y, por ende, no entran en competencia con las mujeres chilenas (Stefoni 2002).

84 Si Somos Americanos. Revista de Estudios Transfronterizos 
(Vásquez 2004:92-93; Cortez 2004:156). La Encuesta Casen 2006 revela que el 11,6 por ciento de las familias peruanas en el país no reside con sus hijas e hijos menores de 18 años (Stefoni et al. 2008:12).

El hecho de que Perú y Chile sean países fronterizos posibilita llevar a cabo constantes viajes en períodos de vacaciones o fiestas familiares y sociales; además, la legislación vigente es poco clara y casi nula respecto de los procedimientos de migración familiar. En este contexto, la migración infantil puede llevarse a cabo con cierta flexibilidad o sin la solicitud de visados, en comparación con otros contextos altamente burocratizados, como ocurre por ejemplo en Europa. Sin embargo, esta situación posteriormente obstaculiza el ingreso escolar debido a la falta de documentación. Por su parte, las familias señalan que no disponen del tiempo ni del dinero necesarios para realizar todos los trámites de regularización migratoria (Vásquez 2004, 2007; Stefoni et al. 2008). ${ }^{12}$

\section{La educación de la niñez peruana en Chile: del acceso escolar al desafío de la inte- gración social}

En general, las niñas y los niños de origen extranjero logran acceder a la escolarización obligatoria, pero el tipo de establecimiento al que se integren dependerá de las condiciones socioeconómicas de cada familia inmigrante. Según los datos de la Encuesta Casen 2006, el 51,86 por ciento de la niñez inmigrante accede a la educación pública municipalizada; un 26,44 por ciento a la particular subvencionada; y un 5 por ciento a la particular pagada. ${ }^{13}$ Para el caso específico de las familias peruanas, y dado que pertenecen a las capas medias-bajas y más pobres, sus hijas e hijos ingresan mayormente a la educación pública ( 45,8 por ciento) y, en menor medida, a la particular subvencionada (32,2 por ciento) (Stefoni et al. 2008:19). ${ }^{14}$

12 Para llevar a cabo el ingreso es preciso la legalización y el pago de documentos en su país de origen, solicitud de matrícula en alguna escuela (radicación) o solicitud de visado de estudiante. Pero en ocasiones se genera un círculo vicioso ya que el colegio exige el visado infantil para iniciar la matrícula regular, y a su vez en el consulado peruano en Chile solicita el certificado de estudiante regular de la escuela para tramitar el visado (Vásquez 2004).

13 Según datos de la matrícula escolar del año 2005, del total de 3.779.459 estudiantes, 23.500 son extranjeros y de estos aproximadamente el 45 por ciento está en situación irregular (Mardones 2006:6, 29).

14 Para el caso argentino, la mayoría accede a la educación pública (57,3 por ciento), en menor medida a la particular subvencionada (23,7 por ciento) o particular (3,3 por ciento). Para el caso de Ecuador se constatan las diferencias económicas porque un 20 por ciento ingresa a la educación municipal, un 36 por ciento a la particular subvencionada y un 20 por ciento a la particular pagada (Stefoni et al. 2008:19). 
Cuando las familias inmigrantes intentan gestionar el ingreso escolar en Chile pueden tener variadas experiencias dependiendo de la clase social, el barrio donde viven, las redes sociales de contacto y la nacionalidad como ejes estratificadores. Las familias peruanas provenientes de niveles bajos y medio-bajos se enfrentan a una serie de dificultades logísticas para organizar el proceso de matrícula por falta de tiempo -debido a las largas jornadas laborales- y especialmente por las carencias económicas que les impiden poder acceder a una educación de calidad. De acuerdo a un estudio realizado por Stefoni et al. (2008) por encargo de la OIM, los problemas de las familias peruanas son acuciantes. Si bien la normativa vigente señala explícitamente que las autoridades deben dar todas las facilidades para el ingreso escolar, en concreto las familias peruanas más pobres encuentran una serie de obstáculos en el proceso de escolarización y finalmente acaban siendo discriminadas de la mayoría de los establecimientos educacionales ya sea por falta de cobertura, solicitud de documentación excesiva o racismo manifiesto. ${ }^{15}$

Los padres y especialmente las madres inmigrantes buscan los centros escolares que estén cerca de sus domicilios y que sean "recomendados" por sus amistades y parientes que ya tienen escolarizados a sus hijas e hijos en ese lugar; es decir, a través de los contactos con sus propias redes migratorias, como afirmarían Portes, Landolt y Guarnizo (2003) "desde abajo". Generalmente estos colegios se caracterizan por su "buena" voluntad en la acogida de niñez inmigrante y porque en estos lugares acaban siendo matriculados la mayoría de las niñas y los niños extranjeros que son rechazados de los otros centros. De este modo, en estos colegios se desencadena un proceso de alta concentración de población escolar migrante y son centros que están localizados en determinados barrios de algunas comunas de la capital, justamente donde habitan las comunidades migrantes. Dentro del mapa migratorio santiaguino conocidas son las escuelas República Alemania y República Panamá -por nombrar las más emblemáticas-, las cuales se caracterizan por una gran apertura y acogida a la niñez inmigrante. Las escuelas con un 30 por ciento o más de matrícula extranjera ya comienzan a ser estigmatizadas como "escuelas de inmigrantes" (Mardones 2006:14; Stefoni et al. 2008:38 y ss.). ${ }^{16}$

${ }^{15}$ En el año 2001, el Ministerio de Educación publicó el instructivo "Convivencia escolar y derecho a la educación"; en el año 2003 elaboró una nueva normativa llamada "Por el derecho a la educación. Integración, diversidad y no discriminación"; en el año 2005 publicó el instructivo "Sobre el ingreso, permanencia y ejercicio de los alumnos/as migrantes en los establecimientos educacionales que cuentan con reconocimiento oficial" (Decreto Ministerial No 1108, 2 de septiembre de 2005).

${ }^{16}$ La Escuela República Alemania registra un 29,4 por ciento de población inmigrante, en ella se canta el himno nacional de Perú y ha sido centro de votación para las elecciones peruanas. Por su parte, la Escuela República Panamá tiene un 16 por ciento de niñas y niños extranjeros (Mardones 2006:17). 
A pesar de que el Estado chileno garantiza efectivamente el acceso escolar a la niñez inmigrante, esto no es suficiente para lograr el gran desafío de la integración social en las aulas, en los patios y en las relaciones sociales que se dan en el entorno escolar. Además de los factores estructurales comentados recientemente existe una serie de problemáticas de tipo sociocultural como el racismo y la discriminación que sufren cotidianamente las niñas, los niños y sus familias en los colegios y barrios donde viven, que ahora pasamos a revisar (Stefoni et al. 2008:67, 69, 74). ${ }^{17}$

\section{Experiencias de discriminación y racismo de la niñez peruana en Chile: "me gusta la piel blanquita de las chilenas"}

A partir de los conceptos teóricos y los datos del contexto comentados recientemente, en este apartado se analizan algunos extractos de las entrevistas realizadas a las niñas y los niños peruanos en Santiago de Chile. A efectos analíticos organizamos el apartado en tres categorías de análisis, cada una de las cuales constituye una dimensión temática en el análisis de las experiencias de discriminación y racismo de la niñez migrante. Las categorías son: el color de la piel y el fenotipo; la personalidad y la nacionalidad. Cabe mencionar que el análisis de los discursos infantiles se realiza a partir de la consideración de la perspectiva de género como un eje transversal en dichas experiencias.

\section{Color de la piel y fenotipo}

La experiencia migratoria de las niñas y los niños en Chile está fuertemente marcada por las constantes situaciones de discriminación y racismo de las cuales son víctimas. De las entrevistas y el trabajo de campo realizado en Santiago se desprende que existen diversos factores asociados a estas situaciones, como el color de la piel, los rasgos fenotípicos, las supuestas características de la personalidad y la nacionalidad como eje articuladores de la discriminación y el racismo. En el siguiente relato de Matías se observa que el color de la piel de sus compañeros de clase es una característica que les otorga la legitimidad necesaria para burlarse de él. Cabe mencionar que estas prácticas de discriminación suceden dentro del grupo infantil, es decir, a nivel intrageneracional. Estrella, por su parte, reconoce explícitamente su predilección por el supuesto color de la piel más "blanco" de las niñas chilenas en comparación con el eventual tono moreno de

17 "Mantener alta concentración de matrículas priva a los niños/as chilenos de aprender a aceptar y valorar la alteridad; contribuye a estigmatizar a ciertos grupos y crea condiciones de vida que no son las reales para los niños o niñas" (Stefoni et al. 2008:80). 
los niños peruanos, como una forma de relacionar determinados estereotipos de género con ciertas nacionalidades (Pavez 2010a, 2010b). Su estimación respecto del color de la piel es plenamente coherente con los valores dominantes de la sociedad chilena y, presumiblemente, de la cultura occidental (Van Dijk 2003). Por otro lado, cabe mencionar que las mujeres chilenas de clase media y alta entrevistadas por Stefoni (2002:131) valoran positivamente a una mujer peruana -para que realice el trabajo doméstico en sus hogares- cuando es "más blanca" que sus connacionales.

No me gusta que me molesten todos mis compañeros de colegio. Sí, no sé, porque son blancos, porque se creen, no sé. (Matías, 10 años, Santiago)

A mí de las mujeres me gusta su piel, porque son blanquitas así las chilenas. Los peruanos tienen gusto también, no voy a decir que son morenos, por eso, no, que sean feos, no, son bonitas las pieles también. (Estrella, 12 años, Santiago)

En el siguiente fragmento de la entrevista realizada a Rosario también se analizan las divergencias en los tonos de la piel, que en su caso se atribuyen a las condiciones climáticas de los lugares de origen y de destino. En su opinión se aprecia que el color moreno de la piel puede ser considerado un defecto ("era muy negrito; yo no tengo defecto, no tengo nada mal"). Cuando las niñas peruanas -en este caso Rosario- son víctimas de discriminación racial, pueden llegar a responder utilizando la violencia ("yo también le ofendería") y la deslegitimación del grupo opresor ("habla mal, habla groserías"), como una forma de actuar frente a una situación de vulnerabilidad, también a nivel intrageneracional, dentro del colectivo infantil (Pavez 2010a, 2010b):

Sí, porque algunas niñas chilenas son más claras porque nacen acá. Y allá [en Perú] porque no hace tanto frío y acá [en Chile] da como tormenta, allá chispea nomás y después pasa un rato y te pones short y todo lo que tú quieras. Sí, porque yo sé [...] O sea, allá en Perú se queman más con el sol, porque allá hace mucho calor. [...] Allá, cuando estaba en segundo, había un niño que se llamaba Bernardo y era muy negrito, y entonces le decían "chocolito mascao", y a él le ofendía. Y la tía que lo tenía que defender, decía: "Al menos él tiene sus bonitos dientes que son blanquitos y tú tienes todos los dientes amarillos".

¿AQUÍ EN CHILE A TI TE HA PASADO ESO POR SER PERUANA?

No, porque yo antes... no, yo no tengo defecto, no tengo nada mal, nada, y si alguien me molestara, yo le daría altiro en la...

¿LE PEGARÍAS? 
Sí, porque me está ofendiendo y yo también le ofendería, porque como habla mal, habla groserías, le digo grosero. (Rosario, 9 años, Santiago)

La entrevistada, Lucía, muestra una supuesta aceptación y respeto de parte de la sociedad peruana hacia todas las personas, sin importar su color de piel, una idea que se basa en la igualdad humana ("a nosotros no nos importa... somos iguales"), pero en la misma frase ella realiza una hipérbole ("blancona") para denostar los tonos claros de la piel, presumiblemente atribuidos a las personas chilenas. Por su parte, Aurora enfatiza otro aspecto clave en el racismo discursivo, el cual se refiere al fenotipo "peruano" ("parece igualita a peruana"), que probablemente está relacionado tanto con el color de la piel y con ciertos rasgos físicos que son la base ideológica de la discriminación. Esta opinión apunta indirectamente hacia lo que García (2008) denomina "la condición inmigrante" de las niñas y los niños provenientes de familias extranjeras. En este caso concreto, observamos que dicha "condición inmigrante" es una construcción social e histórica difícil de definir en términos analíticos, porque va más allá del tono de la piel, el idioma, la nacionalidad o el fenotipo, pero, a la vez, contiene estas características y las tensiona en las relaciones generacionales, de género y de clase social (Pavez 2010a, 2010b):

Porque [a] nosotros no [nos] importa que el otro sea negra, blancona. [...] No importa del color que sea: nosotros somos iguales. (Lucía, 9 años, Santiago)

Yo tengo una amiga que vive conmigo; ella es chilena pero parece peruana. En el colegio [a los peruanos] los tratan bien. (Aurora, 9 años, Santiago)

\section{La personalidad}

En la siguiente frase de Arturo se insinúan unas supuestas características de la personalidad chilena en términos de superioridad frente a las nacionalidades fronterizas como la peruana o boliviana. Según Van Dijk $(2003,2005)$, una de las formas en que opera el racismo discursivo es mediante el énfasis de los rasgos positivos del grupo dominante ("los chilenos no los molestan porque somos más choros que todos los de América del Sur") y la minimización de las características activas de los grupos oprimidos o excluidos ("los peruanos hablan así"). De este modo se logra que incluso las propias personas deslegitimadas acaben incorporando dicha presunción como una verdad ("yo los miro así, sí, tienen razón”).

Estas cuestiones que señala Arturo son similares al estudio realizado por la Fundación Ideas, cuyos resultados muestran que el 47 por ciento de las personas chilenas en- 
trevistadas está de acuerdo con la afirmación: "los chilenos son más patriotas y valientes que sus vecinos" (López 2004). Además, en 2004 un estudio de UNICEF indica que el 46 por ciento de las niñas y los niños de escuelas públicas considera que "una o más nacionalidades vecinas son inferiores a la chilena", opiniones que demuestran el sentimiento de "superioridad" chileno frente a los países limítrofes ya sea por pasados conflictos bélicos (marítimos) y porque se atribuye al colectivo peruano, boliviano o ecuatoriano un mayor componente indígena. Por otro lado, en Chile también existen graves dificultades para valorar las propias raíces de los pueblos originarios mapuche, rapanui o aymará, los cuales son permanentemente descalificados y criminalizados por la sociedad chilena y viven en condiciones de exclusión social, política y económica. Es evidente la intolerancia y los prejuicios hacia todo lo que atente contra lo chileno, es decir, contra la pretendida homogeneidad cultural chilena que fue exaltada durante la dictadura militar y consolidada durante estos años de democracia (Merino et al. 2007:149). ${ }^{18}$

Molestan mucho. Dicen que a todos los países de América del Sur los molestan por un dejo que tienen. Por ejemplo, los peruanos que hablan así; los bolivianos, no sé, los argentinos dicen que [...] Y ya cuando estamos en la sala dicen que no, a los chilenos no los molestan porque somos más choros que todos los de América del Sur y yo los miro así, sí, tienen razón, sí. Y lo malo, que algunas personas te discriminan por ser peruano, te molestan, eso. Pero hay que saber escoger amigos. (Arturo, 14 años, Santiago)

\section{La nacionalidad}

La segunda cuestión descrita recientemente en el relato de Arturo, tiene que ver con que la nacionalidad opera como marca o estigma de la exclusión ("te discriminan por ser peruano") en las redes de amistad. En el contexto de las migraciones contemporáneas en Chile, la nacionalidad constituye un signo étnico que se transforma en la marca o el estigma de la discriminación. Debido a la importante presencia del colectivo peruano en el país y a la discriminación que existe en su contra, se yergue una especie de peruanización de la migración (Cortez 2007:113; Reyes 2007:140; Pavez 2010a, 2010b). En otras palabras, en Chile la condición de ser "peruano" funciona a un nivel simbólico como sinónimo de "inmigrante", mientras que en otros contextos -como el europeo- la mayor

18 En un estudio llevado a cabo por Merino et al. (2007) en la ciudad de Temuco (territorio originario de la comunidad mapuche), se constata que alrededor del 80 por ciento de sus habitantes no mapuches manejan un discurso prejuiciado y estereotipado respecto de los mapuches. Si bien se valora al mapuche que luchó por su independencia y libertad como símbolo del primer chileno, por otro lado se discrimina y se siente vergüenza por el mapuche actual. 
carga simbólica se atribuye a la categoría "inmigrante", fundamentalmente "ilegal", como parámetros de pertenencia y/o exclusión en la sociedad de destino (Santamaría 2002). ${ }^{19}$

La siguiente opinión de Kasumi también se ancla en la peruanización de la migración, al analizar las dificultades de integración social que ella experimenta en la sociedad chilena por el hecho de ser peruana. Las violentas experiencias de discriminación racial y xenófoba que Kasumi vive se ven acentuadas por la frustración que implica el incumplimiento de sus expectativas respecto de Chile ("yo pensaba que era... que iba a ser más fácil adaptarme"). Ella esperaba que su acomodación en el lugar de destino fuera menos traumática a raíz de lo que su madre le había comentado. El texto de Kasumi muestra la situación de vulnerabilidad que experimenta una niña peruana inmigrante en Chile en términos de nacionalidad, generación y género -agudizado por la precariedad de su posición de clase social-, puesto que la persona que la violenta con un lenguaje discriminatorio y altamente ofensivo es un hombre, chileno y adulto, es decir, una persona que se encuentra en una posición de poder legitimada para realizar este tipo de actos racistas en contra de ella en el espacio público:

No sé, si tú eres peruana las personas te miran raro. A veces hay personas que te dicen en la calle "oye peruana culiá", que esto, que lo otro [...] No sé... cuando yo estaba en Perú, lo que me había explicado mi mamá, cómo era este país. Yo pensaba que era... que iba a ser más fácil adaptarme. Pero un día que yo estaba yendo a la casa de la hermana de mi papá, que también vive acá y es peruana, estábamos yendo y un señor bien viejito, tranquilo, me agarra y comienza a insultarnos y a decir "peruanas culiás". Entonces nosotras quedamos, así, espantadas, como que nunca pensamos que nos iban a decir eso. Bueno yo principalmente, porque yo pensaba que te iban a insultar cuando tú los ofendías o algo así, pero no así de la nada. (Kasumi, 13 años, Santiago)

Por último, la entrevista realizada conjuntamente a Sofía y Alexia también habla sobre la peruanización como un estigma de discriminación, esta vez en el comercio. La posición de clase social, generación y género de las niñas agudiza la vulnerabilidad de ser extranjeras. Por esta razón, las personas adultas chilenas en vez de tratarlas como "clientas", las discriminan por ser "peruanas":

19 En el Congreso chileno se encuentra en discusión el Proyecto de ley que establece Medidas contra la Discriminación (Boletín 3.815-07). El proyecto ha terminado su tramitación y se encuentra con urgencia simple, el 18 de octubre de 2005 ingresa a segundo trámite al Senado y actualmente solo falta una votación en pleno. Este proyecto orienta en las distintas normas sobre la no discriminación (Convenciones Internacionales y Constitución chilena) para garantizar de forma efectiva la igualdad ante la ley (Stefoni et al. 2008:92). 
Me discriminaron a mí y a mi amiga. Estábamos paradas en una tienda. "Nos da una bebida", dijimos, y una señora respondió: "a los peruanos no les damos". (Sofía, 9 años, Santiago)

La señora que le dijo "me puede dar una bebida", la señora estaba adentro y el señor estaba afuera, pero no era un quiosco, sino como una casa y estaban hablando así. Y el señor dijo...no, a los peruanos no, a los peruanos no les damos". Eso fue cerca del colegio, cuando estábamos llegando ya al colegio con... allá por un este... acá ¿no cierto? que hay un parque, como por acá en el Hospital San Juan, ahí hay un quiosco que dice Viceroy, así como, venden diarios y hay un teléfono, ahí. (Alexia, 9 años, Santiago)

Este conjunto de citas extraídas de las entrevistas realizadas muestran la complejidad del fenómeno migratorio peruano en Chile, que es vivido con particulares matices por parte de las niñas y los niños participantes de este estudio. La información recientemente analizada se enriquece con los datos extraídos de la observación participante. En las anotaciones realizadas durante la observación en las escuelas públicas de la comuna de Santiago-centro se constata que algunas niñas chilenas utilizan la categoría nacional para burlarse de los niños extranjeros, utilizando la nacionalidad o ciertos elementos culturales del país de origen como el propio insulto. Por ejemplo, en el taller de danzas se ensayan bailes del folclor latinoamericano. Cuando alguna niña o niño canta la canción de su país de origen como Saya peruana o Tinku boliviano, las niñas chilenas se burlan. De este modo, la peruanización o bolivianización de las migraciones otorga nuevos significados a la categoría simbólica de inmigrante, dotándola de un contenido acorde al contexto chileno contemporáneo.

Especialmente, en las sesiones del taller de danzas en la Escuela República de Colombia se ha conversado en varias ocasiones con Hugo, un niño peruano de 9 años. A veces se muestra animado por participar en una entrevista de este estudio, pero finalmente desiste porque siente "vergüenza". Al interior de su curso, Hugo es llamado ofensivamente "chocolate", como una forma de remarcar el tono moreno de su piel, ante lo cual el niño responde de diversas formas en función de si es una niña o un niño quien lo molesta. Hugo intenta compensar su situación de desventaja étniconacional corrigiendo el acento chileno -que tiende a la economía del lenguaje- de sus compañeras y compañeros de aula. De este modo, intenta situarse en una posición de superioridad en un aspecto académico para revertir, de algún modo, la vulnerabilidad de su "condición inmigrante". Pero las niñas y los niños de origen chileno evaden sus críticas argumentando que "en Chile se habla así", es decir, recordándole las normas sociales del lugar de destino y remarcando su condición de extranjero para 
que se adapte, situación que frustra visiblemente a Hugo. Él es integrado en el grupo masculino compuesto principalmente por niños chilenos y despliega con ellos una masculinidad agresiva a través de los juegos y las peleas, a pesar de que se burlan de él por sus rasgos fenotípicos. Cuando su compañera de aula, Rosemarie -entrevistada en este estudio-, en tanto niña y peruana, también se burla de él, Hugo le responde con violencia física y verbal. Ante esta situación de constante discriminación, Hugo extiende una estrategia de subversión para intentar "deshacerse" de su identidad nacional -entendida como la causa de su discriminación- a través de no participar en los bailes peruanos y rechazarlos vehementemente. Sin embargo, en otras ocasiones Hugo llora porque se siente excluido de los bailes y lamenta que sus compañeros lo discriminen por ser peruano, demostrando las complejas contradicciones que él siente ante su "condición inmigrante".

Por su lado, Rosemarie logra ejercer un liderazgo en los juegos y conversaciones al interior del grupo femenino, compuesto por niñas chilenas y extranjeras. Pero este liderazgo se debilita ante la presión que ejercen los varones como grupo cohesionado y generalmente la niña cede ante las opiniones masculinas. En este caso, la nacionalidad opera como un factor de exclusión en convergencia con el género, aunque la sólida personalidad de la niña compensa las categorías de vulnerabilidad. A diferencia de Hugo, Rosemarie es ofendida por su condición de género y no de nacionalidad, con el apodo de Bruja. La niña responde con agresividad a los varones chilenos y peruanos que la molestan, $\mathrm{y}$ a algunas niñas también, pero generalmente a estas últimas las ignora. Hugo, en tanto varón e inmigrante, carga con la "etnicidad" de su nacionalidad y despliega estrategias masculinas, como la agresividad, para reposicionarse efectivamente. En cambio, Rosemarie, por su condición de género y origen nacional, es acosada y discriminada principalmente a través de los estereotipos de género, los cuales se agudizan en una "feminidad inmigrante". Ella responde con variadas estrategias en estas situaciones, algunas más femeninas, como ceder ante las opiniones masculinas y otras más cercanas a la masculinidad, como agredir o ser indiferente.

Por último, en la Escuela República de Panamá se observa que las niñas y los niños de origen chileno y peruano se burlan y excluyen de sus juegos a Matías - un niño peruano de 9 años entrevistado en este estudio- por su aspecto físico, su situación emocional (normalmente se lamenta de vivir sin su madre biológica) y también por su condición migratoria (incluso por sus pares de origen peruano). En esas situaciones Matías responde utilizando la violencia. Al interior de su curso Matías tiene la etiqueta de "niño problema", vulnerando gravemente sus derechos a la dignidad y al buen trato. 


\section{CONCLUSIONES}

En el escenario de las migraciones contemporáneas hacia Chile, la nacionalidad peruana es utilizada como una marca o un estigma de discriminación (negativa) que junto a la clase social, el género y la edad articulan la experiencia migratoria de las niñas y los niños. Particularmente, en los sectores más pobres la nacionalidad es una cualidad que acentúa la discriminación y la exclusión socioeconómica que ya les afecta a las familias migrantes. Especialmente, las personas peruanas son las que padecen las peores consecuencias por su precaria situación económica, ya que solo pueden acceder a viviendas en sectores altamente vulnerables y deben soportar los prejuicios racistas que existen en su contra. Si bien se dan las oportunidades para que las niñas y los niños peruanos ingresen al sistema escolar, habitualmente se pretende que se asimilen a las prácticas y discursos del alumnado chileno, dado que desde el Estado no se promueven programas de atención y gestión de la diversidad en el ámbito escolar, social y comunitario.

Como se aprecia en la cita periodística que encabeza este artículo, existe un claro sentimiento xenófobo e intolerante en la sociedad chilena que afecta en mayor medida a las personas de origen peruano y en situación de exclusión social. Por lo tanto, es indispensable y urgente que se diseñen programas curriculares desde un enfoque de la interculturalidad para revertir las prácticas y discursos discriminatorios. La ausencia de una política pública que gestione el hecho migratorio desde la perspectiva de la inclusión social y la interculturalidad se hace patente y muestra las flaquezas de un sistema escolar público paupérrimo que reproduce las desigualdades estructurales entre las propias clases sociales chilenas y además acentúa las desventajas de los grupos migrantes.

En la actualidad, la inmigración actúa como un fenómeno sociológico que refleja y cuestiona las profundas desigualdades y vulneraciones que se viven al interior de la propia sociedad chilena. Los discursos y las prácticas de las niñas y los niños peruanos muestran que la discriminación y el racismo están muy arraigados, incluso la reproducen. Es necesario que desde la sociedad de acogida se acompañen los procesos de la niñez inmigrante con el objetivo de garantizar el respeto y un trato no discriminatorio. El reconocimiento de las niñas y los niños migrantes como actores sociales contribuye a facilitar su integración en la sociedad de destino y, de este modo, abrir reales oportunidades de movilidad e inclusión social en Chile.

Por último, la investigación sobre la participación infantil en los procesos migratorios contemporáneos es un campo de estudios sociológicos emergente en las ciencias sociales en general. El estudio de la niñez migrante permite articular diversos aportes para, 
por un lado, dialogar críticamente con otras áreas de investigación sociológica como los estudios de géneros, migratorios y de las infancias. Y, por otro lado, coadyuvar a incidir políticamente en el debate público de la sociedad latinoamericana respecto del fenómeno migratorio, la construcción/subversión del género y la comprensión de la niñez "moderna".

\section{REFERENCIAS}

Alanen, Leena. 1994. "Gender and generation: feminism and the 'child question." Pp. 27-41 en Childhood matters: social theory, practice and politics, Vol. 14, editado por Jens Qvortrup et al. Viena: Avebury-European Centre Vienna.

Alegre, Miquel Àngel. 2007. Geografies adolescents a secundària. Posicionaments culturals $i$ relacionals dels i les joves dorigen immigrant. Barcelona: Observatori Català de la JoventutGeneralitat de Catalunya.

Cortez, Ana. 2004. "Integración de los niños y niñas inmigrantes al sistema escolar chileno: obstáculos y desafíos." Pp. 163-72 en Niños y niñas inmigrantes en Chile: derechos y realidades, editado por Colectivo Sin Fronteras. Santiago: Editorial Colectivo Sin Fronteras-Fundación Anide-KinderNotHilfe.

. 2007. "La migración internacional: un desafío para las políticas públicas en Chile." Pp. 105-18 en Niños y niñas inmigrantes en Chile: derechos y realidades, editado por Colectivo Sin Fronteras. Santiago: Editorial Colectivo Sin Fronteras-Fundación Anide-KinderNotHilfe.

Departamento de Extranjería y Migración. Ministerio del Interior. 2008. Caracterización de la inmigración y política migratoria en Chile. Consultado julio 31, 2010 (http://www.incami.cl/ archivosUpload/caracterizacion por ciento20e por ciento20instructivo por ciento20politica por ciento20migratoria por ciento20septiembre por ciento202008.ppt).

.2009. Informe anual de permisos otorgados y estimación de población de extranjeros en Chile a diciembre de 2009. Consultado julio 28, 2010 (http://www.extranjeria.gov.cl/ filesapp/Informe por ciento20Estimacion por ciento20Poblacion por ciento20Extranjeros por ciento202008.pdf).

2010. Estadísticas migratorias. Permanencias definitivas otorgadas por el Departamento de Extranjería y Migración período 1995-2009. Consultado julio 28, 2010 (http:// www.extranjeria.gov.cl/estadisticas_mig.html). 
2010. Estadísticas migratorias. Permisos de residencia temporal otorgados por el Departamento de Extranjería y Migración período 2003-2009. Consultado junio 28, 2010 (http://www.extranjeria.gov.cl/estadisticas_mig.html).

Elqueda, Pamela. 2008. "Escolares chilenos aceptan más a los peruanos si adoptan nuestra cultura por sobre la propia.” El Mercurio, septiembre 11 de 2008. Consultado agosto 8, 2010 (http:// diario.elmercurio.cl/detalle/index.asp?id $=\{3208828 b-6573-4 d 91-8143-383584987 b a 4\})$.

Flores, Reginaldo. 2007. "El fenómeno inmigratorio en Chile: iniciativas gubernamentales destinadas a niños, niñas y adolescentes.” Pp. 95-104 en Niños y niñas inmigrantes en Chile: derechos y realidades, editado por Colectivo Sin Fronteras. Santiago: Editorial Colectivo Sin Fronteras-Fundación Anide-KinderNotHilfe.

Frønes, Ivan. 1994. "Dimensions of Childhood." Pp. 145-64 en Childhood Matters: Social Theory, Practice and Politics, Vol. 14, editado por Jens Qvortrup et al. Viena: Avebury-European Centre Vienna.

Gaitán, Lourdes. 2006a. "La nueva sociología de la infancia. Aportaciones de una mirada distinta." Política y Sociedad 43 (1):9-26.

. 2006b. Sociología de la Infancia. Madrid: Síntesis.

2008. Los niños como actores en los procesos migratorios. Madrid: Universidad Complutense de Madrid.

García, Iñaki. 2008. "Herederos de la condición inmigrante: adolescentes y jóvenes en familias madrileñas de origen extranjero". Tesis Doctoral, Departamento de Sociología I, UNED, Madrid.

Instituto Nacional de Estadísticas (INE). 2003. Resultados generales Censo 2002 Chile. Santiago: Mideplan.

James, Allison y Alan Prout, eds. [1997] 2010. Constructing and reconstructing childhood. Contemporary issues in the sociological study of childhood. Oxon: Routledge.

Jenks, Chris. [1996] 2005. Childhood. Oxon: Routledge.

López, María José. 2004. “Aceptación, integración y democracia. Desafíos éticos de la inmigración peruana en Chile." Perspectivas Éticas 9:9-41.

Mardones, Pablo. 2006. "Exclusión y sobre-concentración de la población escolar migrante bajo un modelo de segregación socio-territorial." Informe final del concurso: Migraciones y modelos de desarrollo en América Latina y el Caribe. Programa Regional de Becas Clacso. 
Martínez, Jorge. 2003a. El encanto de los datos. Sociodemografía de la inmigración en Chile según el Censo de 2002. Serie Población y Desarrollo 49. Santiago: CEPAL.

2003b. El mapa migratorio de América Latina y El Caribe, las mujeres y el género. Serie Población y Desarrollo 44. Santiago: CEPAL.

Mayall, Berry. 2000. “The sociology of childhood in relation to children's rights." The International Journal of Children's Rights 8:243-59.

. [2002] 2009. Towards a sociology for childhood. Thinking from children's lives. Glasgow: Open University Press-McGraw-Hill Education.

Merino, María Eugenia, Mauricio Pilleux, Daniel Quilaquo y Berta San Martín. 2007. "Racismo discursivo en Chile. El caso mapuche." Pp. 137-79 en Racismo y discurso en América Latina, coordinado por Teun Van Dijk. Barcelona: Gedisa.

Organización Internacional de las Migraciones (OIM). 2008. Los desafíos de las migraciones en Chile 2008. Santiago: IOM-OIM.

Pavez, Iskra. 2010a. "Los derechos de las niñas y los niños peruanos migrantes en Chile." El Observador 6:62-80.

.2010b. "Los derechos de las niñas y los niños peruanos migrantes en Chile. La infancia como un nuevo actor migratorio." Enfoques 8 (12):27-51.

. 2011a. "Migración infantil: rupturas generacionales y de género. Las niñas peruanas en Barcelona y Santiago de Chile." Tesis doctoral. Departamento de Sociología, Universitat Autònoma de Barcelona.

. 2011b. “¿Quién decide la migración infantil? Niñez y poder en familias peruanas transnacionales." RAYUELA, Revista Iberoamericana sobre Niñez y Juventud en Lucha por sus Derechos 5:103-13.

Pedone, Claudia. 2010. "Introducción. Más allá de los estereotipos: desafíos en torno al estudio de las familias migrantes." Pp. 11-16 en Familias, niños, niñas y jóvenes migrantes. Rompiendo estereotipos, coordinado por Grupo Interdisciplinario de Investigador@s Migrantes. Madrid: IEPALA.

Portes, Alejandro, Patricia Landolt y Luis Guarnizo. 2003. "Introducción. El estudio del transnacionalismo: peligros latentes y promesas de un campo de investigación emergente." Pp. 5-23 
en La globalización desde abajo: transnacionalismo inmigrante y desarrollo. La experiencia de Estados Unidos y América Latina, editado por Alejandro Portes et al. México D.F.: Flacso.

Programa de las Naciones Unidas para el Desarrollo (PNUD). 2010. Desarrollo Humano en Chile 2010. Género: los desafíos de la igualdad. Santiago: PNUD.

Qvortrop, Jens. 1992. "El niño como sujeto y objeto: ideas sobre el programa de infancia en el Centro europeo de Viena." Infancia y Sociedad 15:169-86.

. 1994. "Childhood matters: an introduction." Pp. 1-23 en Childhood matters: social theory, practice and politics, Vol. 14, editado por Jens Qvortrup et al. Viena: AveburyEuropean Centre Vienna.

Reyes, Carlos. 2007. "Niños y niñas sin fronteras en las escuelas." Pp. 133-48, en Niños y niñas inmigrantes en Chile: derechos y realidades, editado por Colectivo Sin Fronteras. Santiago: Editorial Colectivo Sin Fronteras-Fundación Anide-KinderNotHilfe.

Rodríguez, Iván. 2000. “¿Sociología de la infancia? Aproximaciones a un campo de estudio difuso." Revista Internacional de Sociología 26:99-124.

Santamaría, Enrique. 2002. La incógnita del extraño. Sobre la construcción social de la inmigración no comunitaria. Barcelona: Anthropos.

Stefoni, Carolina. 2002. "Mujeres inmigrantes peruanas en Chile." Papeles de Población 33:118-45.

. 2003. Inmigración peruana en Chile. Una oportunidad a la integración. Santiago: Universitaria, Flacso.

. 2004. "Inmigración y ciudadanía: la formación de comunidades peruanas en Santiago y la emergencia de nuevos ciudadanos.” Política 43:319-36.

. 2009. "Migración, género y servicio doméstico. Mujeres peruanas en Chile."

Pp. 191-232 en Trabajo doméstico: un largo camino hacia el trabajo decente, editado por María Elena Valenzuela y Claudia Mora. Santiago: Oficina Internacional del Trabajo.

Stefoni, Carolina, Elaine Acosta, Marcia Gaymer y Francisca Casas-Cordero. 2008. Niños y niñas inmigrantes en Santiago de Chile. Entre la integración y la exclusión. Santiago: OIMUniversidad Alberto Hurtado. 
Suárez, Liliana. 2006. “Un nuevo actor migratorio: jóvenes, rutas y ritos transnacionales.” Pp. 67-100 en Menores tras la frontera. Otra inmigración que aguarda, editado por Francisco Checa Olmos, Ángeles Arjona y Juan Carlos Checa. Barcelona: Icaria.

Suárez-Orozco, Carola y Marcelo Suárez-Orozco. 2003. La infancia de la inmigración. Madrid: Morata.

2008. Históries d'immigració: la comprensió dels patrons de rendiment escolar dels joves immigrants nouvinguts. Serie: Informes Breus No 12 Immigración. Barcelona: Fundació Jaume Bofill.

Fondo de las Naciones Unidas para la Infancia (UNICEF). 2004. Los prejuicios en niños, niñas y adolescentes. Encuesta "La Voz de los Niños sobre Convivencia Escolar y Prejuicios." Consultado marzo 30, 2009 (http://www.unicef.cl/archivos_documento/128/INFORME por ciento202004.pdf).

Van Dijk, Teun. 2003. Racismo discursivo en España y América Latina. Barcelona: Gedisa. 2005. El racismo de las elites. Barcelona: Gedisa.

Vásquez, María Elena. 2004. “Niños y niñas inmigrantes. Contexto general.” Pp. 93-101 en Niños y niñas inmigrantes en Chile: derechos y realidades, editado por Colectivo Sin Fronteras. Santiago: Editorial Colectivo Sin Fronteras-Fundación Anide-KinderNotHilfe.

. 2007. "Intervención local y comunitaria para la integración social de los inmigrantes." Pp. 121-32 en Niños y niñas inmigrantes en Chile: derechos y realidades, editado por Colectivo Sin Fronteras. Santiago: Editorial Colectivo Sin Fronteras-Fundación AnideKinderNotHilfe.

Wintersberger, Helmut. 1992. "La infancia y el cambio. Condiciones de la infancia en la Europa actual." Infancia y Sociedad 15:143-68.

. 1994. "La infancia moderna." Pp. 31-46 en Investigación y politicas de infancia en Europa en los años 90. Seminario Europeo. Madrid: Ministerio de Asuntos Sociales. 